\title{
Psychological Aspects in Children and Adolescents With Major Thalassemia: A Case-Control Study
}

\author{
Fatemeh Behdani ${ }^{1}$; Zahra Badiee ${ }^{2}$; Paria Hebrani ${ }^{3}$; Fatemeh Moharreri ${ }^{3}$; Amir Hossein \\ Badiee $^{4, *} ;$ Negin Hajivosugh ${ }^{5}$; Zohreh Rostami ${ }^{6}$; Amir Akhavanrezayat ${ }^{5}$
}

${ }^{1}$ Department of Psychiatry, Psychiatry and Behavioral Sciences Research Center, Mashhad University of Medical Sciences, Mashhad, IR Iran

${ }_{2}^{2}$ Department of Child and Adolescent Hematology, Mashhad University of Medical Sciences, Mashhad, IR Iran

${ }_{4}^{3}$ Department of Child and Adolescent, Mashhad University of Medical Sciences, Mashhad, IR Iran

${ }_{5}^{4}$ Mashhad University of Medical Sciences, Mashhad, IR Iran

${ }^{5}$ Student Research Committee, Mashhad University of Medical Sciences, Mashhad, IR Iran

${ }_{\text {Ibn-e-Sina Hospital, Mashhad University of Medical Sciences, Mashhad, IR Iran }}^{\text {Student Research Committee, Mashhad University of Medical Sciences, Mashh }}$

${ }^{*}$ Corresponding author: Amir Hossein Badiee, Mashhad University of Medical Sciences, Mashhad, IR Iran. E-mail: behdanif@mums.ac.ir

Received: February 10, 2014; Accepted: November 11, 2014

\begin{abstract}
Background: Thalassemia is an inherited blood disease. It is a serious public health problem throughout the Mediterranean region, the Middle East and the Indian subcontinent, as well as in Southeast Asia.

Objectives:Thalassemia is an inherited blood disease. It is a serious public health problem. In this study we assessed psychological aspects in Iranian children and adolescents with thalassemia major.

Patients and Methods: In this case-control study sixty healthy subjects aged 7-18 years and Sixty Patients with confirmed diagnosis of major thalassemia were enrolled. After obtaining informed consent from parents of all participating thalassemia patients and healthycontrols, we assessed psychological aspects and quality of life by Pediatric Quality of LifeTM (PedsQL ${ }^{\mathrm{TM}}$ ), Strengths and Difficulties Questionnaires (SDQ), State and Trait Anxiety, Children's Depression Inventory(CDI).

Results: The results of this study indicate that there are significant changes in depression, anxiety, QOL and behavioral screening between children with thalassemia major compared with healthy subjects by means of both parents and children reports. According to the results, children with thalassemia major have more psychological problems than healthy ones. Patients with thalassemia have a lower QOL than their peers $(\mathrm{P}=0.001)$, the rate of depression is higher in this group $(\mathrm{P}=0.015)$, Also behavioral problems in these children are more than healthy subjects $(\mathrm{P}=0.009)$.

Conclusions: We recommend appropriate treatment and counseling procedures in addition to specific treatment of thalassemia. According to the results we suggest to establish pediatric psychiatric clinics beside thalassemic clinics to cure psychological aspects of the disease.
\end{abstract}

Keywords: Adolescents; Children; Quality of Life; Thalassemia Major

\section{Background}

Thalassemia is an inherited blood disease. It is a serious public health problem throughout the Mediterranean region, the Middle East and the Indian subcontinent, as well as in Southeast Asia (1). Out of approximately 300 million carriers of this hemoglobin disorder worldwide (2). Among the Estern Mediterranean region, Iran is one of the major centers for the prevalance of Beta-thalassemia.It is estimated that there are between 2-3 million B-thalassemia carriers and 25,000 patients in Iran (3). Beta-thalassemia is a chronic and genetically determined hematological disorder characterized by severe hemolytic anemia as a result of deficient synthesis of $\beta$ chains of the hemoglobin. The anemia demands frequent blood transfusions to maintain life, while hemosiderosis and other complications of the disease require a continuous and distressing treatment regimen that in- cludes parenteral iron chelation treatment and regular medical supervision. Thalassemia is a chronic disease that presents a range of serious clinical and psychological challenges. The effects of thalassemia on physical health can lead to physical deformity, growth retardation, and delayed puberty (4-6). Its impact on physical appearance, e.g. bone deformities and short stature, also contributes to a poor self-image $(5,6)$. Severe complications such as heart failure, cardiac arrhythmia, liver disease, endocrine complications, and infections are common among thalassemia patients $(7,8)$. Despite the critical advances in the knowledge of the psychological assessment in chronic patients, very few studies are carried out to investigate correlation between psychological conditions and quality of life in Thalassemia major (TM) patients (9-11). As the mean age and life expectancy

Copyright (C) 2015, Growth \& Development Research Center. This is an open-access article distributed under the terms of the Creative Commons Attribution-NonCommercial 4.0 International License (http://creativecommons.org/licenses/by-nc/4.0/) which permits copy and redistribute the material just in noncommercial usages, provided the original work is properly cited. 
Behdani F et al.

of TM patients expands, psychosocial issues related to quality of life become an increasingly important focus of attention $(12,13)$. It is universally known that chronic diseases have a psychological implication, which in pediatric age has a great importance. Children with chronic physical illnesses exemplified by thalassemia are vulnerable to emotional and behavioral problems (14). The onset of symptoms, the rigors of treatment, and frequent absence from school make huge demands on the emotional and interpersonal resources of the children and their families. The emotional and cognitive needs of a child with thalassemia are patently different from those of the adolescents striving for independence and identity. Adults with thalassemia face problems related to career, finding partners, establishing a family (due to infertility) and waning social support as parents age. Thus each age group has problems unique to that stage of development. However, the increasing longevity of children with thalassemia has brought psychological problems to the fore. Various authors have reported that up to $80 \%$ of children with thalassemia are likely to have psychological problems e.g. oppositional defiant disorder, anxiety disorders and depression (15-17). Although children with all types of blood disorders are exposed to similar stressors, those with thalassemia are unique in that they have to attend hospital regularly for blood transfusions (18). Clemente et al. 2002, concluded that specific blood disorders have differential impact on affected children, resulting in higher rates of psychological disturbances in children with thalassemia (17). A Quality of Life (QOL) study in adolescents with thalassemia indicates that those with psychiatric symptoms had poorer QOL (5).

\section{Objectives}

There is a dearth of studies that address QOL across different age groups in children with thalassemia. In this study we aimed to assess psychological aspects and QOL in Iranian children and adolescents with thalassemia major compared with control group.

\section{Patients and Methods}

This is a Case-Control study. Sixty healthy subjects aged 7-18 years were also enrolled from pediatric clinics for routine checks, chronic diseases were ruled out in all of them. Sixty children and adolescents (aged 7-18 years) with confirmed diagnosis of major thalassemia were referred to Sarvar pediatric thalassemia clinic, Mashhad, Iran. The study was approved by the ethical committee on human research of Mashhad University of Medical Sciences. After obtaining informed consent from parents of all participating thalassemic patients and healthy controls, we assessed psychological aspects and quality of life by Pediatric Quality of LifeTM (PedsQL ${ }^{\mathrm{TM}}$ ), Strengths and Difficulties Questionnaires (SDQ), State and Trait Anxiety, Children's Depression Inventory (CDI).

\subsection{Questionnaire Measures}

\subsubsection{Strengths and Difficulties Questionnaires (SDQ)}

The SDQ is a brief questionnaire that can be administered to the parents and teachers of 4- to 16-year-olds and to 11- to 16-year-olds themselves (19-21). Besides covering common areas of emotional and behavioral difficulties, it also enquires whether the informant thinks that the child has a problem in these areas. The algorithm makes separate predictions for three groups of disorders, namely conduct-oppositional disorders, hyperactivity-inattention disorders, and anxiety-depressive disorders. Each is predicted to be unlikely, possible or probable. Predictions of these three groups of disorders are combined to generate an overall prediction about the presence or absence of any psychiatric disorder. A specificity of 95\% (95\% Cl $94.1-95.1 \%)$ and a sensitivity of $74 \%(59.7-66.9 \%)$ is identified in Iranian pediatric population (22).

\subsubsection{Pediatric Quality of LifeTM (PedsQL $L^{\mathrm{TM}}$ )}

The Peds QLTM 4.0 questionnaire was used for four different age groups: 2-4, 5-7, 8-12 and 13-18 years of age, and included four different fields of children's function: physical function, emotional function, social function and school (and pre-school courses) function. PedsQLTM has children forms (for 5-7, 8-12, 13-18 year old children) which were filled by children, and parents' forms (for 2-4, 5-7, 8-12, 13-18 year old children) which were filled by their parents. Each question could get one of the five scores of 0 for "never" up to 4 for "almost always"; the total score was calculated by dividing the added score of different sections over the number of answered questions (7) and an ideal score was 100. PedsQLTM was translated to Persian language and had a validity value of more than 0.7 when filled by the patient or his/her parents. The test and its repetition showed a high reliability in parents' reports (0.68-0.79) and a medium to high reliability in children's reports $(0.46-0.73)(23)$.

\subsubsection{Children's Depression Inventory (CDI)}

The Children's Depression Inventory $(C D I)(24,25)$ is a 27 item scale designed for use with children aged 8-14 years. Each item consists of three statements that describe the absence, presence, and severity of the symptom within the last 2 weeks. For each item, the child's score ( 0 , I, or 2 ) is in the direction of the depression. The children read the items themselves or have the items read to them. The reliability and validity of the CDI are well established and norms for prepubertal children have been developed (25). The CDI has been shown to discriminate between depressed and nondepressed children $(26,27)$. Its internal reliability is high $(27,28)$.

\subsubsection{Child State-Trait Anxiety Inventories (SATA)}

This inventory, developed by Spielberger (29) has 2 sub- 
scales, each composed of 20 multiple choice questions for state trait anxiety. Each item is scored as 0,1 , or 2 according to the severity of the symptom. State anxiety defines the experienced anxiety under certain conditions and at a certain time and changes according to external factors. On the other hand, trait anxiety defines the feelings of the individual in general and reflects the individual's general predisposition to anxiety. Its internal reliability is high (29).

\subsection{Statistical Analysis}

The collected data were analyzed using the SPSS program, version 16 . The results were calculated in each group and compared between two groups. The Chisquare test and independent test were used to determine the difference between various variables, and the P-value was set as $<0.05$ for significance.

\section{Results}

Sixty patients with thalassemia major and 60 healthy participants were enrolled in the study. Fifty six (46.67\%) participants were females and 64 (53.33\%) males. The mean scores of different subscales of SDQ, SATA and QOL are presented in Table 1 . According to the results, no significant difference was observed in depression between patients with and without growth disorder in thalassemia major group $(P=0.56)$. In addition, there were no specific differences in anxiety, QOL and behavioral screening between patients with and without growth disorder in thalassemia major group. Tables 2 and 3 show the mean scores of depression in CDI. There is no signifi- cant difference between males and females regarding subscales of SDQ in thalassemic patients and healthy participants. No significant differences were observed in depression between different ages (children, 8-11 years and adolescents, 12-18 years) in thalassemic group ( $\mathrm{P}=$ 0.56). Furthermore, there were no significant differences in anxiety and QOL between different ages in the group of thalassemia major. In Table 4, thalassemia and healthy subjects are compared by means of depression, anxiety and $\mathrm{QOL}(\mathrm{P}=0.015, \mathrm{P}=0.034, \mathrm{P}=0.001$, respectively $)$. Also there were significant differences in behavioral problems (SDQ) including emotional, conduct, hyperactivity, peer relationship, social and all states between two groups $(\mathrm{P}=0.01, \mathrm{P}=0.01, \mathrm{P}=0.03, \mathrm{P}=0.03, \mathrm{P}=0.02, \mathrm{P}$ $=0.009$, respectively). Table 5 shows a significant difference in QOL between major thalassemia and healthy groups $(P=0.04)$. In addition, significant differences were seen in behavioral problems (SDQ) including emotional, conduct, hyperactivity, peer relationship, social and all states between two groups $(\mathrm{P}=0.039, \mathrm{P}<0.001, \mathrm{P}$ $=0.03, \mathrm{P}=0.01, \mathrm{P}=0.02, \mathrm{P}<0.001$, respectively). Table 6 shows that there was a significant difference in QOL between children and parents' sight in major thalassemia group ( $\mathrm{P}<0.001)$. Also significant changes were seen in some of behavioral screenings including emotional, social and all states between children and parents' sight in major thalassemia group $(\mathrm{P}=0.001, \mathrm{P}<0.001, \mathrm{P}<0.001$, respectively). In contrast, no significant differences were seen in other behavioral screenings including conduct, hyperactivity, peer relationship between children and parents' viewpoints in major thalassemia group ( $\mathrm{P}=$ $0.28, \mathrm{P}=0.91, \mathrm{P}=0.39$, respectively).

\begin{tabular}{lcc}
\hline Table 1. Demographic Characteristics of Patients with Thalassema Major ${ }^{\mathrm{a}}$ & & \\
\hline Variable & Major Thalassemia Group & Control Group \\
\hline Age, $\mathbf{y}$ & $13.18(3.69)$ & $31(51.7)$ \\
\hline Gender & $33(5.22)$ \\
\hline Male & $27(45)$ & $29(48.3)$ \\
\hline Female & & \\
\hline Physical disorders & $7(11.7)$ & \\
\hline Diabetes & $4(6.7)$ \\
\hline Heart failure & $28(46.7)$ \\
\hline Skin discoloration & $40(66.7)$ \\
\hline Face changes & $31(51.6)$ \\
\hline Growth disorder & $52(86.7)$ \\
\hline Desferal injection & $1.88(1.50)$ \\
\hline Age at the first desferal injection & 1 \\
\hline Min & 7 \\
\hline Max & $17.65(3.28)$ \\
\hline Number of blood transfusions received during a year & 13 \\
\hline Min & 26 \\
\hline Max & \\
\hline Data are presented as No. (\%) or No. & & \\
\hline
\end{tabular}


Behdani F et al.

Table 2. Psychological Problems Between Male and Female in Group With Thalassemia Major From Viewpoint of Children ${ }^{a, b}$

\begin{tabular}{|lccc|}
\hline Variable & Male & Female & PValue \\
\hline Depression & $8(24.2)$ & $8(29.6)$ & 0.77 \\
\hline Anxiety & & & 0.571 \\
\hline \multicolumn{1}{c}{ Low state, low trait } & $5(15.2)$ & $3(11.1)$ & \\
\hline High state, low trait & $20(60.6)$ & $13(48.1)$ & \\
\hline Low state, high trait & $2(6.1)$ & $2(7.4)$ & \\
\hline High state, high trait & $6(18.2)$ & $9(33.3)$ & \\
\hline QOL & & & \\
\hline Low & $2(6.1)$ & $2(7.4)$ & \\
\hline Medium & $7(21.2)$ & $3(11.1)$ & \\
\hline Good & $11(33.3)$ & $10(37)$ & \\
\hline Perfect & $13(39.4)$ & $12(44.4)$ & \\
\hline
\end{tabular}

SDQ

Emotional

0.129

$\begin{array}{lcc}\text { Low } & 1(4.5) & 1(5) \\ \text { Medium } & 30(91) & 20(75) \\ \text { Good } & 1(4.5) & 5(20)\end{array}$

Conduct

$\begin{array}{lcc}\text { Low } & 4(13.6) & 3(10) \\ \text { Medium } & 13(40.9) & 18(65) \\ \text { Good } & 15(45.5) & 7(25)\end{array}$

Hyperactivity

0.051

$\begin{array}{lcc}\text { Low } & 0 & 0 \\ \text { Medium } & 30(90.9) & 19(70) \\ \text { Good } & 3(9.1) & 8(30)\end{array}$

\section{Peer relationship}

0.589

$\begin{array}{lcc}\text { Low } & 3(9.1) & 1(5) \\ \text { Medium } & 25(77.3) & 20(75) \\ \text { Good } & 4(13.6) & 5(20)\end{array}$

Social

0.224

$\begin{array}{lcc}\text { Low } & 0 & 0 \\ \text { Medium } & 31(95.5) & 24(90) \\ \text { Good } & 1(4.5) & 3(10)\end{array}$

All states 0.14

$\begin{array}{lrc}\text { Low } & 4(13.6) & 11(40) \\ \text { Medium } & 15(45.5) & 9(35) \\ \text { Good } & 13(40.9) & 7(25)\end{array}$

a Abbreviations: QOF, Quality of Life; SDQ, strengths and difficulties questionnaires.

$\mathrm{b}$ Data are presented as No. (\%)

Table 3. Psychological Problems Between Male and Female in Healthy Subjects From Children Viewpoint a,b

\begin{tabular}{lccc}
\hline Variable Variable & Male & Female & P Value \\
\hline Depression & $1(3.2)$ & $4(13.8)$ & 0.18 \\
Anxiety & & & 0.294 \\
\hline \multicolumn{1}{l}{ Low state, low trait } & $5(16.1)$ & $11(37.9)$ & \\
\hline High state, low trait & $18(58.1)$ & $13(44.8)$ & \\
\hline Low state, high trait & $2(6.5)$ & $1(3.4)$ & \\
High state, high trait & $6(19.4)$ & $4(13.8)$ & \\
\hline QOL & & & 0.39 \\
\hline
\end{tabular}

QOL

$\begin{array}{lcc}\text { Low } & 0 & 0 \\ \text { Medium } & 0 & 1(4.3) \\ \text { Good } & 11(35.5) & 7(24.1) \\ \text { Perfect } & 20(64.5) & 21(72.4)\end{array}$

SDQ

Emotional

$\begin{array}{lcc}\text { Low } & 0 & 0 \\ \text { Medium } & 30(95.7) & 27(92) \\ \text { Good } & 1(4.3) & 2(8)\end{array}$

Conduct

0.281

$\begin{array}{lcc}\text { Low } & 0 & 2(8) \\ \text { Medium } & 26(82.6) & 23(80) \\ \text { Good } & 5(17.4) & 3(12)\end{array}$

Hyperactivity

0.18

$\begin{array}{lcc}\text { Low } & 0 & 0 \\ \text { Medium } & 26(82.6) & 28(96) \\ \text { Good } & 5(17.4) & 1(4)\end{array}$

Peer relationship

0.447

\begin{tabular}{lccc} 
Low & $1(4.3)$ & 0 & \\
Medium & $27(87)$ & $24(84)$ & \\
Good & $3(8.7)$ & $5(16)$ & \\
Social & & & 0.35 \\
Low & 0 & 0 & \\
Medium & $30(95.7)$ & $24(84)$ & \\
Good & $1(4.3)$ & $5(16)$ & \\
All states & & & 0.73 \\
Low & $1(4.3)$ & $2(8)$ & \\
Medium & $23(73.9)$ & $19(64)$ & \\
Good & $7(21.7)$ & $8(28)$ & \\
\hline
\end{tabular}

${ }^{\mathrm{a}}$ Abbreviations: QOF, Quality of Life; SDQ, strengths and difficulties questionnaires.

$\mathrm{b}$ Data are presented as No. (\%) 
Behdani F et al.

Table 4. Psychological Problems Between Two Groups From Children Viewpoint ${ }^{\mathrm{a}, \mathrm{b}}$

\begin{tabular}{lccc}
\hline Variable & Major Thalassemia Group & Healthy Group & P Value \\
\hline Depression & $8(13.33)$ & $3(4.17)$ & 0.015 \\
Anxiety & & & 0.034 \\
\hline Low state, low trait & $4(6.67)$ & $9(15)$ & \\
\hline High state, low trait & $17(27.50)$ & $12(20)$ & \\
\hline Low state, high trait & $2(3.33)$ & $5(7.50)$ & $5(7.50)$ \\
\hline High state, high trait & $8(12.50)$ & & 0.0015 \\
\hline
\end{tabular}

QOL

0.001

$\begin{array}{lcc}\text { Low } & 2(3.33) & 0 \\ \text { Medium } & 5(8.33) & 1(0.83) \\ \text { Good } & 11(17.50) & 9(15) \\ \text { Perfect } & 13(20.83) & 21(34.17)\end{array}$

\section{SDQ}

Emotional

Low
Medium
Good
Conduct

$10(16.7)$

$44(73.2) \quad 56(93.7)$

$4(7.1) \quad 4(6.2)$

$\begin{array}{lcc}\text { Low } & 7(11.9) & 3(4.2) \\ \text { Medium } & 31(52.4) & 49(81.2) \\ \text { Good } & 21(35.7) & 9(14.6)\end{array}$

\section{Hyperactivity}

Low
Medium
Good

\section{Peer relationship}

$\begin{array}{lcc}\text { Low } & 10(16.7) & 1(2.1) \\ \text { Medium } & 40(66.7) & 51(85.4) \\ \text { Good } & 10(16.7) & 7(12.5)\end{array}$

\section{Social}

$\begin{array}{lcc}\text { Low } & 9(14.3) & 0 \\ \text { Medium } & 47(78.6) & 54(89.6) \\ \text { Good } & 4(7.1) & 6(10.4) \\ \text { All states } & & \\ \text { Low } & 16(26.2) & 4(6.2) \\ \text { Medium } & 24(40.5) & 41(68.6) \\ \text { Good } & 20(33.3) & 15(25)\end{array}$

$5.7(9.5) \quad 0$

$43(71.4) \quad 54(89.6)$

$11(19) \quad 6(10.4)$

$(9.7)$
$(6.2)$
2)
6)

0.03

0.03 
Behdani F et al.

Table 5. Psychological Problems Between Two Groups From Parents'Viewpoint ${ }^{\mathrm{a}, \mathrm{b}}$

\begin{tabular}{|c|c|c|c|}
\hline Variable & $\begin{array}{l}\text { Major Thalas- } \\
\text { semia Group }\end{array}$ & $\begin{array}{l}\text { Healthy } \\
\text { Group }\end{array}$ & PValue \\
\hline QOL & & & 0.04 \\
\hline Low & $2(3.3)$ & 0 & \\
\hline Medium & $10(16.7)$ & $3(5)$ & \\
\hline Good & 19 (31.7) & $16(26.7)$ & \\
\hline Perfect & $29(48.3)$ & $41(68.3)$ & \\
\hline \multicolumn{4}{|l|}{ SDQ } \\
\hline Emotional & & & 0.039 \\
\hline Low & $15(25)$ & $6(10)$ & \\
\hline Medium & $39(65)$ & $41(68.3)$ & \\
\hline Good & $6(10)$ & $13(21.7)$ & \\
\hline Conduct & & & $<0.001$ \\
\hline Low & $19(31.7)$ & $5(8.3)$ & \\
\hline Medium & $23(38.3)$ & $45(75.3)$ & \\
\hline Good & $18(30)$ & $10(16.7)$ & \\
\hline Hyperactivity & & & 0.03 \\
\hline Low & $10(16.7)$ & $2(3.3)$ & \\
\hline Medium & $37(61.7)$ & $47(78.3)$ & \\
\hline Good & $13(21.7)$ & $11(18.3)$ & \\
\hline $\begin{array}{l}\text { Peer } \\
\text { relationship }\end{array}$ & & & 0.01 \\
\hline Low & $7(11.7)$ & 0 & \\
\hline Medium & $43(71.7)$ & $52(86.7)$ & \\
\hline Good & $10(16.7)$ & $8(13.3)$ & \\
\hline Social & & & 0.02 \\
\hline Low & $9(15)$ & $1(1.7)$ & \\
\hline Medium & $46(76.7)$ & $51(85)$ & \\
\hline Good & $5(8.3)$ & $8(13.3)$ & \\
\hline All states & & & $<0.001$ \\
\hline Low & $22(36.7)$ & $4(6.9)$ & \\
\hline Medium & $18(30)$ & $42(70.7)$ & \\
\hline Good & $20(33.3)$ & $13(22.4)$ & \\
\hline
\end{tabular}

a Abbreviations: QOF, Quality of Life; SDQ, strengths and difficulties questionnaires.

$\mathrm{b}$ Data are presented as No. (\%)
Table 6. Psychological Problems Between Children and Parents' Viewpoints in Major Thalassemia Group a,b

\begin{tabular}{lccc}
\hline Variable & Children & Parents & PValue \\
\hline QOL & $2(3.33)$ & $8(12.50)$ & \\
\hline Low & $5(8.33)$ & $20(32.50)$ & \\
Medium & $11(17.50)$ & $3(5)$ & \\
Good & $13(20.83)$ & 0.001 \\
Perfect & & & 0.001 \\
\hline SDQ & & & \\
\hline
\end{tabular}

Emotional

\begin{tabular}{lcc} 
Low & $10(16.7)$ & $19(31.7)$ \\
\hline Medium & $46(76.2)$ & $23(38.3)$ \\
Good & $4(7.1)$ & $18(30)$
\end{tabular}

Conduct

0.28

$\begin{array}{lll}\text { Low } & 7(11.9) & 10(16.7) \\ \text { Medium } & 31(52.4) & 37(61.7) \\ \text { Good } & 21(35.7) & 13(21.7)\end{array}$

\section{Hyperactivity}

0.91

\begin{tabular}{lcr}
\hline Low & $6(9.5)$ & $7(11.7)$ \\
\hline Medium & $43(71.5)$ & $43(71.7)$ \\
\hline Good & $11(19)$ & $10(16.7)$
\end{tabular}

Peer relation-

ship

\begin{tabular}{lcc} 
Low & $10(16.7)$ & $9(15)$ \\
\hline Medium & $40(66.7)$ & $46(76.7)$ \\
\hline Good & $10(16.7)$ & $5(8.3)$ \\
\hline Social & $9(14.3)$ & $22(36.7)$ \\
\hline Low & $47(78.6)$ & $18(30)$ \\
Medium & $4(7.1)$ & $20(33.3)$ \\
\hline
\end{tabular}

All states

$<0.001$

$\begin{array}{lcc}\text { Low } & 16(26.2) & 4(6.7) \\ \text { Medium } & 27(45) & 47(78.3) \\ \text { Good } & 20(33.3) & 9(15)\end{array}$

a Abbreviations: QOF, Quality of Life; SDQ, strengths and difficulties questionnaires.

$\mathrm{b}$ Data are presented as No. (\%) 
Behdani F et al.

\section{Discussion}

The results of this study indicate that there are significant differences in depression, anxiety and QOL and behavioral screening between children with thalassemia major compared with healthy subjects by means of both parents and children reports. According to the results, children with thalassemia major have more psychological problems than healthy ones. Also parents assessed not only their children's quality of life but also emotional and social behavior significantly worse than their children ( $\mathrm{P}<0.001$ ). Hadi et al. (30) observed that QOL in terms of physical health and its related aspects was lower in patients with thalassemia major than in control group. Also Shaligram et al. (31) foun that in thalassemia major group $74 \%$ had a low quality of life. The results of these two studies are similar to our findings. In an other study that was conducted by Masera et al. (32), 80 percent of children with thalassemia major had at least one psychiatric disorder. In the study conducted by Khani et al. (33) in Mazandaran province, Iran, $64.9 \%$ of patients with thalassemia major had no psychological problems. The result of our study indicate that patients with thalassemia had a high risk of psychiatric disorders and therefore may require psychological counseling. Depression is one of the most common psychiatric disorders in patients with thalassemia major. According to our results $26.7 \%$ of patients were depressed, this was significantly more than in control group. In the study by Ghaffari Saravi et al. (34) in Sari city in Iran depression was assessed in 165 children with thalassemia. According to the results of this study, depression in patients with thalassemia major (14\%) was significantly higher $(5,5 \%)$ than in the control group. The rate of depressive symptoms in our study is higher than that of Ghaffari Saravi et al. (34). In the Shaligram et al. (31) study depressive symptoms were reported in $62 \%$ of thalassemia patients that is the highest rate reported in recent studies. In a other study by Cakaloz et al. (35) on 25 thalassemic patients the psychiatric diagnosis was significantly higher $(55.0 \%)$ in the children with TM as compared to the control group (14.7\%). The thalassemic children showed an anxiety disorder frequency of 30.0\% and a depressive disorder frequency of $15.0 \%$. This study had a small sample size compared to our study. In the study of Ghanizadeh et al. (36) on 110 children and adolescents with TM, about 49\% suffered from depressive symptoms which is more than our results (26.7\%). According to our results the state of anxiety in children with TM was significantly higher than in healthy children. In our study low trait, high state and high trait, high state were higher in TM children which Indicates the higher stress level in patients with thalassemia. Similarly, Aydin et al. (37) found that hopelessness and trait-anxiety score were significantly higher in patients with thalassemia major than the in control group. Also in a study by Cakaloz et al. (35) children with thalassemia showed greater Anxiety disorder (30\%). In our study, overall behavioral prob- lems were seen more in children with thalassemia than in control group. Although the rate of conduct problems was lower in thalassemic group. In contrst to Shaligram et al. (31) study that have shown conduct disorder to be high (49\%) in children with thalassemia, our findings did not confirm it. We compared QOL from the viewpoints of children and their parents. Parents assessed their children's quality of life significantly lower than their children themselves. Similarly, Alavi et al. (38) observed too, that parents assessed their children's quality of life significantly lower than their children. In our study, there were no significant differences in depression between male and female children with TM; anxiety symptoms were higher in female group. In addition, our female group had a higher QOL than males. Mikelli and Tsiantis (5) in 2004 showed that girls with TM had a lower depression and a higher quality of life than the boys with TM. They reported lower levels of depression Compared to the present study. Alavi (38) found that QOL in girls was worse than in boys just in physical aspects. It can be concluded that patients with thalassemia due to disease progress and its problems have a lower QOL than their peers and the rate of depression is higher in this group. Also behavioral problems in these children are in a lower level than in healthy subjects. We recommend appropriate treatment and counseling procedures in addition to specific treatment of thalassemia. According to the results we suggest to establish pediatric psychiatric clinics in beside thalassemic clinics to cure psychological aspects of the disease.

\section{Acknowledgements}

The results described in this paper were part of a thesis (Proposal No. 6644) by Amir Hossein Badiee (MD). The authors would like to thank the vice chancellery of research of Mashhad University of Medical Sciences and declare that they have no conflicts of interest in the research. We appreciate our collogues in hospitals for co-operation in this research.

\section{References}

1. Weatherall D. 2003 William Allan Award address. The Thalassemias: the role of molecular genetics in an evolving global health problem. Am J Hum Genet. 2004;74(3):385-92.

2. Angastiniotis M, Modell B. Global epidemiology of hemoglobin disorders. Ann NYAcad Sci. 1998;850:251-69.

3. Rezaee AR, Banoei MM, Khalili E, Houshmand M. Beta-Thalassemia in Iran: new insight into the role of genetic admixture and migration. ScientificWorldJournal. 2012;2012:635183.

4. De Sanctis V, Roos M, Gasser T, Fortini M, Raiola G, Galati MC, et al. Impact of long-term iron chelation therapy on growth and endocrine functions in thalassaemia. J Pediatr Endocrinol Metab. 2006;19(4):471-80.

5. Mikelli A, Tsiantis J. Brief report: Depressive symptoms and quality of life in adolescents with b-thalassaemia. J Adolesc. 2004;27(2):213-6.

6. Telfer P, Constantinidou G, Andreou P, Christou S, Modell B, Angastiniotis M. Quality of life in thalassemia. Ann N Y Acad Sci. 2005;1054:273-82.

7. Caro JJ, Ward A, Green TC, Huybrechts K, Arana A, Wait S, et al. 
Impact of thalassemia major on patients and their families. Acta Haematol. 2002;107(3):150-7.

8. Cohen A. Management of iron overload in the pediatric patient. Hematol Oncol Clin North Am. 1987;1(3):521-44.

9. Aydinok Y, Erermis S, Bukusoglu N, Yilmaz D, Solak U. Psychosocial implications of Thalassemia Major. Pediatr Int. 2005; 47(1):84-9.

10. Di Palma A, Vullo C, Zani B, Facchini A. Psychosocial integration of adolescents and young adults with thalassemia major. Ann NY Acad Sci.1998;850:355-60.

11. Ratip S, Modell B. Psychological and sociological aspects of the thalassemias. Semin Hematol. 1996;33(1):53-65.

12. Yang HC, Chen YC, Mao HC, Lin KH. [Illness knowledge, social support and self care behavior in adolescents with beta-thalassemia major]. Hu Li Yan Jiu. 2001;9(2):114-24.

13. Georganda ET. The impact of thalassemia on body image, selfimage, and self-esteem. Ann NY Acad Sci.1990;612:466-72.

14. Eiser C. Psychological effects of chronic disease. J Child Psychol Psychiatry. 1990;31(1):85-98.

15. Beratis S. Psychosocial status in pre-adolescent children with beta-thalassaemia. J Psychosom Res. 1993;37(3):271-9.

16. Tsiantis J, Dragonas T, Richardson C, Anastasopoulos D, Masera $\mathrm{G}$, Spinetta J. Psychosocial problems and adjustment of children with beta-thalassemia and their families. Eur Child Adolesc Psychiatry.1996;5(4):193-203.

17. Clemente C, Tsiantis J, Sadowski H, Lee C, Baharaki S, Ba G, et al. Psychopathology in children from families with blood disorders: a cross-national study. Eur Child Adolesc Psychiatry. 2002;11(4):151-61.

18. Sharghi A, Karbakhsh M, Nabaei B, Meysamie A, Farrokhi A. Depression in mothers of children with thalassemia or blood malignancies: a study from Iran. Clin Pract Epidemiol Ment Health 2006;2:27.

19. Goodman R. The Strengths and Difficulties Questionnaire: a research note. J Child Psychol Psychiatry. 1997;38(5):581-6.

20. Goodman R. The extended version of the Strengths and Difficulties Questionnaire as a guide to child psychiatric caseness and consequent burden. J Child Psychol Psychiatry. 1999;40(5):791-9.

21. Goodman R, Meltzer H, Bailey V. The Strengths and Difficulties Questionnaire: a pilot study on the validity of the self-report version. Eur Child Adolesc Psychiatry. 1998;7(3):125-30.

22. Shahrivar Z, Tehrani-Doost M, Pakbaz B, Rezaie A, Ahmadi F. Normative data and psychometric properties of the parent and teacher versions of the strengths and difficulties questionnaire (SDQ) in an Iranian community sample. J Res Med Sci. 2009;14(2):69-77.
23. Varni JW, Seid M, Rode CA. The PedsQL ${ }^{\mathrm{TM}}$ : Measurement Model for the Pediatric Quality of Life Inventory. Med Care. 1999;37(2):126-39.

24. Kovacs M. Rating scales to assess depression in school-aged children. Acta Paedopsychiatr. 1981;46(5-6):305-15.

25. Smucker MR. . The children's depression inventory: Norms and psychometric analysis.. : Pennsylvania State Univ; 1982.

26. Carlson GA, Cantwell DP. A survey of depressive symptoms, syndrome and disorder in a child psychiatric population.J Child Psychol Psychiatry. 1980;21(1):19-25.

27. Helsel WJ, Matson JL. The assessment of depression in children: the internal structure of the Child Depression Inventory (CDI) Behav Res Ther.1984;22(3):289-98.

28. Saylor CF, Finch AJ, Spirito A, Bennett B. The children's depression inventory: a systematic evaluation of psychometric properties. $J$ Consult Clin Psychol.1984;52(6):955-67.

29. Spielberger CD. The measurement of state and trait anxiety: conceptual and methodological issues. Emotions Their parameters and measurement. 1975;2:713-25.

30. Hadi N, Karami D, Montazeri A. Health-related quality of life in major thalassemic patients. Payesh . 2009;8(4):387-93.

31. Shaligram D, Girimaji SC, Chaturvedi SK. Psychological problems and quality of life in children with thalassemia. Indian J Pediatr. 2007;74(8):727-30.

32. Masera G, Monguzzi W, Tornotti G, Lo Iacono B, Pertici S, Spinetta J. Psychosocial support in thalassemia major: Monza center's experience. Haematologica.1990;75 Suppl 5:181-90.

33. Khani Iurigh H, Majdi MR, Montazeri A. Mental health status of beta-thalassemia major in Mazandaran Province in 2006. Quart Fundam Ment Health . 2007;9(35 \& 36):85-96.

34. Ghaffari Saravi V, Zarghmi M, Ebrahimi E. The prevalence of depression in Thalassemic patients in the city of Sari. Iran J Psychiatry Clin Psychol. 2004;9(3):33-40.

35. Cakaloz B, Cakaloz I, Polat A, Inan M, Oguzhanoglu NK. Psychopathology in thalassemia major. Pediatr Int. 2009;51(6):825-8.

36. Ghanizadeh A, Khajavian S, Ashkani H. Prevalence of psychiatric disorders, depression, and suicidal behavior in child and adolescent with thalassemia major. $J$ Pediatr Hematol Oncol. 2006;28(12):781-4.

37. Aydin B, Yaprak I, Akarsu D, Okten N, Ulgen M. Psychosocial aspects and psychiatric disorders in children with thalassemia major. Acta Paediatr Jpn. 1997;39(3):354-7.

38. Alavi A., Parvin N, Kheiri S, Hamidi zade S, Tahmasebi S. Comparison of perspective of children with major thalassemia and their parents about their quality of life in Shahrekord. J Shahrekord Univ Med Sci. 2007;8(4):35-41. 